\title{
PENILAIAN DAYA TARIK WISATA AI SIPATN LOTUP PERUNTAN DI DESA SAPEKABUPATEN SANGGAU
}

\author{
(Assessment of Sipatn Lotup's Tourism Attraction Demands In Sape Village Sanggau District)
}

\author{
Yulius Efendi, Slamet Rifanjani, Sarma Siahaan \\ Fakultas Kehutanan Universitas Tanjungpura Pontianak. Jl. Daya Nasional Pontianak 78124 \\ E-mail: yuliusfendi762@gmail.com
}

\begin{abstract}
Ecotourism is one of the tourism activities that are environmentally sound by prioritizing aspects of nature conservation, aspects of socio-cultural empowerment of local communities and aspects of learning and education. Attractiveness is a factor that makes people want to visit and see directly to a place that has such an attraction. Ai Sipatn Lotus Peruntan is a hot spring in Cape Village in the protected forest area. During this time, many local villagers used Ai Sipatn Lotus Peruntan for recreation and for skin treatment because they believed they could cure skin diseases. The potential of Ai Sipatn Lotus Peruntan can be developed for Ecotourism Attractiveness, but there is not much presence of Ai Sipatn Lotus Peruntan, new visitors to some of the surrounding communities. Therefore the attractiveness of hot water sources makes people less aware of the information. The research objective is to assess the hot water attraction of Ai Sipatn Lotus Perun. The study was conducted in Cape Village, Jangkang Sub-District, Sanggau District for \pm 3 weeks in April 2018. The research method used a survey method with the help of a questionnaire. Determination of respondents by accidental sampling. Data analysis by scoring and weighting refers to the ADO-ODTWA guideline of the 2003 PHKA DirectorGeneral. Assessment results of Ai Sipatn Hot Springs Lotus Peruntan Tourism Attraction on value elements of 157.33 After being obtained multiplied by the weight value of the assessment criteria of Ai Hot Springs tourist attraction Sipatn Lotus Peruntan which has a weight of 6, so that the value obtained for the assessment criteria for Ai Sipatn Lotus Peruntan Hot Springs tourist attraction to $157.33 \times 6=943.98$ shows that in terms of attractiveness, ODTWA Ai Sipatn lot up peruntan has a value of B or has good appeal.
\end{abstract}

Keywords: attraction, hot water, natural attraction, nature tourism

\section{PENDAHULUAN}

Ekowisata merupakan salah satu kegiatan pariwisata yang berwawasan lingkungan dengan mengutamakan aspek konservasi alam, aspek pemberdayaan sosial budaya ekonomi masyarakat lokal serta aspek pembelajaran dan pendidikan. Menurut Kodhyat (1996) daya tarik wisata adalah segala sesuatu yang mendorong orang untuk berkunjung dan singgah di daerah tujuan wisata yang bersangkutan.
Menurut PHKA (2003) daya tarik merupakan faktor yang membuat orang berkeinginan untuk mengunjungi dan melihat secara langsung ke tempat yang mempunyai daya tarik tersebut. Komponen yang dinilai yaitu 1) Keindahan alam yang terdiri dari kesantaian suasana dan pandangan lepas menuju objek, 2) Jenis sumber daya alam yang menonjol terdiri dari geologi dan flora, 3) Keutuhan sumber daya alam yang terdiri dari lingkungan alam dan flora, 4) 
Kepekaan sumber daya alam yang terdiri dari ada nilai pengetahuan dan ada nilai pengobatan, 5) Pilihan kegiatan rekreasi yang terdiri dari fotografi dan berkemah, 6) Kebersihan udara dan lokasi bersih tidak ada pengaruh yang terdiri dari coretcoret dan binatang, 7) Keamanan yang terdiri dari tidak jalur/arus berbahaya dan tidak ada pencurian, dan 8) Kenyamanan yang terdiri dari bebas bau yang menggangu dan udara sejuk.

Desa sape merupakan kawasan yang terdapat di Kecamatan Jangkang Kabupaten Sanggau Provinsi Kalimantan Barat. Di Desa Sape terdapat wisata sumber air panas Ai Sipatn Lotup Peruntan yang berada di kawasan Hutan Lindung. Ai Sipatn Lotup Peruntan menurut masyarakat desa sape mempunyai khasiat bisa menyembuhkan penyakit kulit hal ini membuat wisata ini menarik untuk dikunjungi karena memiliki keunikan tersebut. Namun pada kenyataannya Ai Sipatn Lotup Peruntan masih banyak masyarakat yang belum mengetahui keberadaan air panas tersebut dikarenakan kurangnya informasi objek wisata tersebut, hal ini dapat dilihat dari pengunjung yang datang hanya sebagian masyarakat dari luar daerah tersebut. Selain itu sampai saat ini pihak terkait yang mengelola kawasan wisata air panas tersebut masih kurang optimal untuk pengelolaan nya, dikarenakan masih kurang memadai sarana dan prasarana, seperti kondisi jalan yang masih hanya jalan tanah dan untuk menuju objek wisata tersebut menempuh jarak $\pm 3 \mathrm{Km}$ dari pusat desa sape.

Ai Sipatn Lotup Peruntan yang kawasannya terjaga perlu dilakukan pemanfaatan potensi sumberdaya alam flora dan fauna serta jasa lingkunganya di kawasan wisata alam mengacu kepada prinsip-prinsip utama ekowisata antara lain ekowisata harus bertumpu pada lingkungan, bermanfaat ekologi, sosial, dan ekonomi bagi masyarakat sekitar, ekowisata harus dapat meningkatkan pemahaman akan lingkungan alam dan budaya, ekowisata harus berkelanjutan, dan ekowisata harus dikelola dengan baik dan menjamin sustainability lingkungan alam yang bertujuan untuk meningkat kesejahteraan generasi sekarang maupun yang akan datang (Aryanto, 2003). Oleh karena itu perlu dilakukan penelitian untuk mengetahui daya tarik wisata air panas Ai Sipatn Lotup Peruntan. Manfaat dari penelitian ini diharapkan dapat memberikan informasi mengenai penilaian daya tarik wisata sumber air panas yang terdapat di Desa Sape Kecamatan Jangkang Kabupaten Sanggau.

\section{METODE PENELITIAN}

Penelitian ini dilakukan di Desa Sape Kecamatan Jangkang Kabupaten Sanggau dengan waktu penelitian \pm 3 minggu selama bulan April 2018. Metode penelitian menggunakan metode survey dengan bantuan kuesioner. Penentuan jumlah pengunjung yang dijadikan responden ditentukan berdasarkan accidental sampling, yaitu seseorang diambil sebagai sampel karena kebetulan orang tersebut berada di lokasi penelitian dan orang tersebut bersedia untuk diwawancarai Mustafa (2000).

Penilaian daya tarik objek wisata Sumber Air Panas Ai Sipatn Lotup Peruntan Di Desa Sape dilakukan dengan 
metode skoring dengan menggunakan pedoman analisis daerah operasi objek dan daya tarik wisata (ADO-ODTWA) Direktur Jendral PHKA (2003) yang telah dimodifikasi sesuai dengan nilai/skor yang telah ditentukan untuk masing-masing kriteria. Adapun nilai bobot tiap kriteria adalah sebagai berikut :

Daya tarik Wisata dengan nilai bobot 6 yaitu berapa banyaknya pengunjung yang datang.

Tabel 1. Kriteria Penilaian Daya Tarik Wisata (Tourist Attraction Assessment Criteria)

\begin{tabular}{|c|c|c|c|c|c|c|}
\hline No & Unsur/Sub unsure & & & Nilai & & \\
\hline 1 & Keindahan Alam & $\begin{array}{l}\text { Ada } 5 \\
(30)\end{array}$ & $\begin{array}{l}\text { Ada } 4 \\
(25) \\
\end{array}$ & $\begin{array}{l}\text { Ada } 3 \\
(20)\end{array}$ & $\begin{array}{l}\text { Ada } 2 \\
(15)\end{array}$ & $\begin{array}{l}\text { Ada } 1 \\
(10)\end{array}$ \\
\hline & $\begin{array}{l}\text { a. Pandangan lepas didalam objek } \\
\text { b. Pandangan lepas menuju objek } \\
\text { c. Keserasian warna } \\
\text { d. Kesantaian suasana } \\
\text { e. Pandangan lingkungan objek }\end{array}$ & & & & & \\
\hline 2 & $\begin{array}{l}\text { Jenis sumber daya alam yang } \\
\text { menonjol }\end{array}$ & $\begin{array}{l}\text { Ada } 5 \\
(30)\end{array}$ & $\begin{array}{l}\text { Ada } 4 \\
(25)\end{array}$ & $\begin{array}{l}\text { Ada } 3 \\
(20)\end{array}$ & $\begin{array}{l}\text { Ada } 2 \\
(15)\end{array}$ & $\begin{array}{l}\text { Ada } 1 \\
(10)\end{array}$ \\
\hline & $\begin{array}{l}\text { a. Geologi } \\
\text { b. Flora } \\
\text { c. Fauna } \\
\text { d. Air } \\
\text { e. Gejala alam }\end{array}$ & & & & & \\
\hline 3 & Keutuhan sumber daya alam & $\begin{array}{l}\text { Ada } 4 \\
(30)\end{array}$ & $\begin{array}{l}\text { Ada } 3 \\
(25)\end{array}$ & $\begin{array}{l}\text { Ada } 2 \\
(20)\end{array}$ & $\begin{array}{l}\text { Ada } 1 \\
(10)\end{array}$ & $\begin{array}{l}\text { Tidak ada } \\
\text { (1) }\end{array}$ \\
\hline & $\begin{array}{l}\text { a. Geologi } \\
\text { b. Flora } \\
\text { c. Fauna } \\
\text { d.Lingkungan alam }\end{array}$ & & & & & \\
\hline 4 & Kepekaan sumber daya alam & $\begin{array}{l}\text { Ada } 4 \\
(30)\end{array}$ & $\begin{array}{l}\text { Ada } 3 \\
(20)\end{array}$ & $\begin{array}{l}\text { Ada } 2 \\
(15)\end{array}$ & $\begin{array}{l}\text { Ada } 1 \\
(10)\end{array}$ & $\begin{array}{l}\text { Tidak ada } \\
\text { (1) }\end{array}$ \\
\hline & $\begin{array}{l}\text { a. Ada nilai pengetahuan } \\
\text { b. Ada nilai kebudayaan } \\
\text { c. Ada nilai pengobatan } \\
\text { d.Ada nilai kepercayaan }\end{array}$ & & & & & \\
\hline 5 & Pilihan Kegiatan rekreasi & $\begin{array}{l}>7 \\
(30)\end{array}$ & $\begin{array}{l}\text { Ada 6-7 } \\
(25)\end{array}$ & $\begin{array}{l}\text { Ada 4-5 } \\
(20)\end{array}$ & $\begin{array}{l}\text { Ada } 2-3 \\
(15)\end{array}$ & $\begin{array}{l}\text { Ada } 1 \\
(10)\end{array}$ \\
\hline & $\begin{array}{l}\text { a. Fotografi } \\
\text { b. Berkemah } \\
\text { c. Bersampan } \\
\text { d. Berenang } \\
\text { e. Menjaring ikan } \\
\text { f. Keindahan alam } \\
\text { g.Memancing ikan }\end{array}$ & & & & & \\
\hline 6 & Kebersihan udara dan lokasi & $\begin{array}{l}>5 \\
(30)\end{array}$ & $\begin{array}{l}\text { Ada } 5 \\
(25)\end{array}$ & $\begin{array}{l}\text { Ada } 4 \\
(20)\end{array}$ & $\begin{array}{l}\text { Ada } 3 \\
(15)\end{array}$ & $\begin{array}{l}\text { Ada 2-1 } \\
\text { (10) }\end{array}$ \\
\hline & $\begin{array}{l}\text { a. Kendaraan bermotor } \\
\text { b. Coret-coret } \\
\text { c. Sampah } \\
\text { d. Binatang } \\
\text { e.Fenomena alam }\end{array}$ & & & & & \\
\hline 7 & Keamanan & $\begin{array}{l}\text { Ada } 5 \\
(30)\end{array}$ & $\begin{array}{l}\text { Ada } 4 \\
(25)\end{array}$ & $\begin{array}{l}\text { Ada } 3 \\
(20)\end{array}$ & $\begin{array}{l}\text { Ada } 2 \\
(15)\end{array}$ & $\begin{array}{l}\text { Ada } 1 \\
(10)\end{array}$ \\
\hline
\end{tabular}




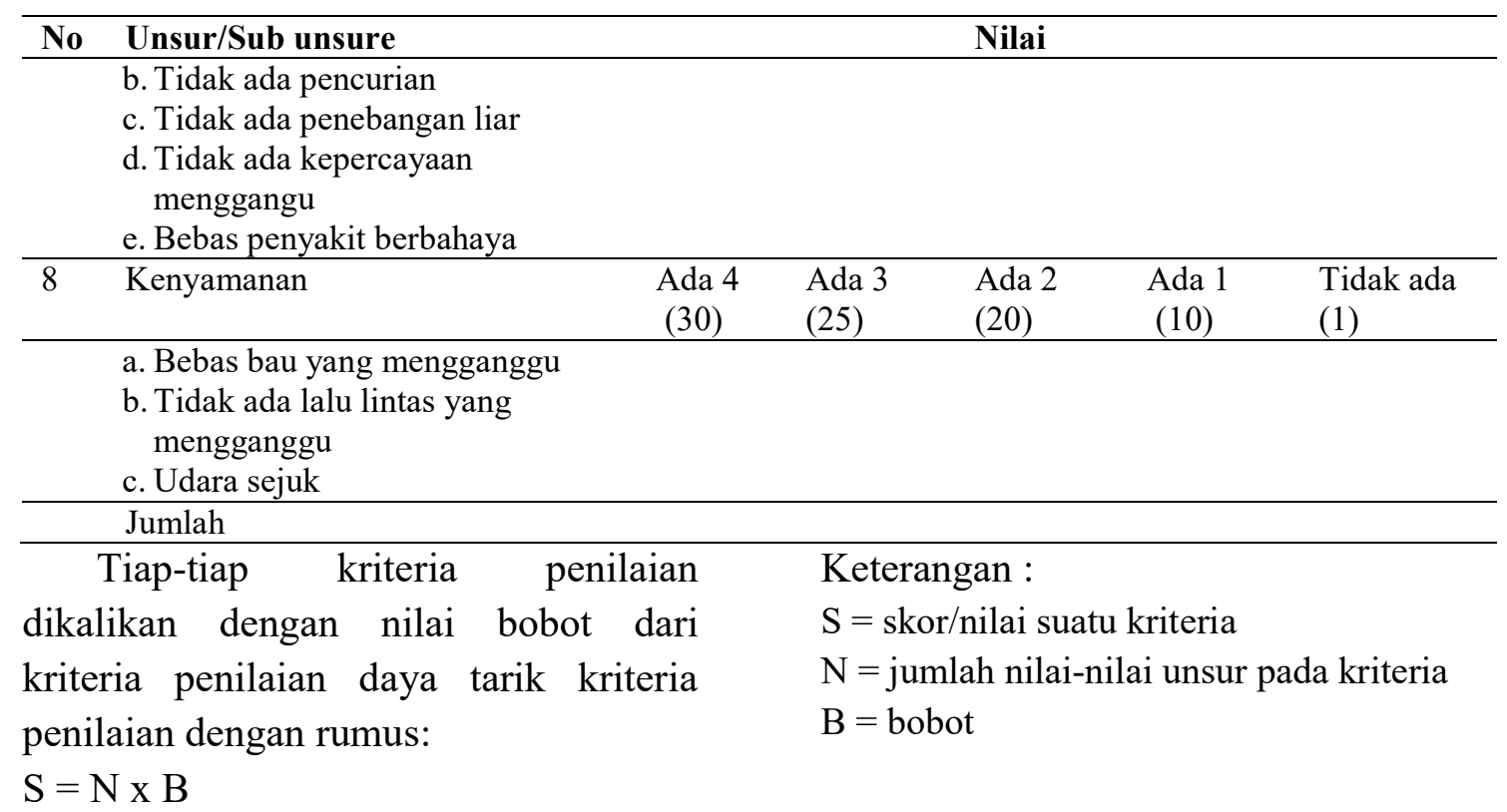

Tabel 2. Klasifikasi Potensi Berdasarkan Nilai Bobot Kriteria Penilaian Daya Tarik Wisata (Classification Potential Based on Weight Value Tourist Attraction Assessment Criteria)

\begin{tabular}{lll}
\hline No & Daya tarik wisata & Penilaian potensi unsure \\
\hline 1 & $1,066-1,440$ & Baik (A) \\
2 & $692-1,066$ & Sedang (B) \\
3 & $318-692$ & Buruk (C) \\
\hline
\end{tabular}

Sumber : Modifikasi Buku Biru (Sarana Ukuran Pembinaan Pengembangan Objek Wisata Alam PHKA 2003)

\section{HASIL DAN PEMBAHASAN}

Hasil penilaian daya tarik wisata di Sumber Air Panas Ai Sipatn Lotup Peruntan Di Desa Sape Kecamatan
Jangkang Kabupaten Sanggau yang berpedoman ADO-ODTWA PHKA tahun 2003 dapat dilihat pada tabel 3.

Tabel 3. Hasil Perhitungan Penilaian Daya Tarik Wisata ( Results of Calculation of Tourist Attraction Assessment )

\begin{tabular}{lll}
\hline No & Unsur & Nilai \\
\hline 1 & Keindahan Alam & 27,12 \\
2 & Jenis sumber daya alam yang menonjol & 23,63 \\
3 & Keutuhan sumber daya alam & 20,90 \\
4 & Kepekaan sumber daya alam & 22,12 \\
5 & Pilihan kegiatan rekreasi & 16,36 \\
6 & Kebersihan udara dan lokasi bersih tidak ada pengaruh & 13,33 \\
7 & Keamanan & 15,60 \\
8 & Kenyamanan & 18,33 \\
\hline & Jumlah & 157,33 \\
\hline
\end{tabular}

Sumber : Data 2018 
Penilaian Daya Tarik Wisata Sumber Air Panas Ai Sipatn Lotup Peruntan pada setiap unsur dan sub unsur setelah didapat nilai sebesar 157,33. Nilai tersebut dikalikan dengan bobot kriteria penilaian daya tarik wisata nilai kriteria penilaian daya tarik wisata Sumber Air Panas Ai Sipatn Lotup Peruntan yang berbobot 6 .

Nilai yang didapat untuk kriteria penilaian daya tarik wisata adalah 157,33 x $6=943,98$. Nilai yang didapat dibandingkan dengan klasifikasi potensi untuk kriteria penilaian daya tarik wisata alam, maka dari hasil perbandingan menunjukkan kawasan Sumber Air Panas Ai Sipatn Lotup Peruntan memiliki daya tarik kawasan dengan nilai (B).

\section{Keindahan alam}

Berdasarkan hasil wawancara dengan pengunjung kawasan yang berada di sumber air panas Ai Sipatn Lotup Peruntan yang membuat sangat menarik adalah air panas dan ekosistem Hutan Lindung yang masih utuh terjaga. Namun berdasarkan unsur pandangan lepas di dalam objek sumber air panas tertutup hal ini disebabkan lokasi kawasan sumber air panas Ai Sipatn Lotup Peruntan tertutup oleh perbukitan pada saat menuju kawasan sumber air panas Ai Sipatn Lotup Peruntan.

\section{Jenis sumber daya alam yang menonjol}

Kawasan Sumber Air Panas Ai Sipatn Lotup Peruntan dari beberapa responden pada unsur sumber daya alam yang menonjol adalah geologi dikarenakan dari awal masuk kawasan adalah jalan bebatuan yang datar dan bebatuan disekitar area objek wisata sumber air panas. Selain itu ditemukan sumber daya alam yang masih melimpah yaitu air disekitar kawasan tersebut karena tidak jauh dari objek yang dituju. Dikawasan air panas tersebut juga ditemukan flora yaitu jenis anggrek yang tumbuh alami, namun berdasarkan unsur gejala alam yang berada disekitar kawasan pada saat hujan deras air yang datang dari hulu sungai bisa menjadi air bah. Jadi untuk pengunjung yang datang tidak diijinkan untuk datang kelokasi.

\section{Keutuhan sumber daya alam}

Berdasarkan dari hasil analisis responden didapat nilai rata-rata 20,90 untuk keutuhan sumber daya alam dikawasan Sumber Air Panas Ai Sipatn Lotup Peruntan. Dan didapat kesimpulan dari para responden yang menilai bahwa kawasan Sumber Air Panas Ai Sipatn Lotup Peruntan memilki keutuhan geologi karena kawasan tersebut masih utuh terjaga dikarenakan banyaknya bebatuan yang menonjol di areal sekitar sumber air panas, selain itu keutuhan lingkungan disekitar kawasan masih terjaga karena masyarakat sekitar yang beradan dekat kawasan tidak merusak tumbuh-tumbuhan yang ada disekitar kawasan sumber air panas Ai Sipatn Lotup Peruntan.

\section{Kepekaan sumber daya alam}

Berdasarkan hasil wawancara dengan pengunjung kawasan yang berada di sumber air panas Ai Sipatn Lotup Peruntan memilki kepekaan yang sangat menonjol adalah nilai pengetahuan yaitu bidang kehutanan dapat dijadikan objek penelitian dan nilai pengobatan yaitu dikarenakan dikawasan tersebut setelah 
orang kampung membuktikan bahwa tempat itu ada Air panas juga waktu itu kakek Ria jadi kepala kampung lalu menyebarkan ke kampung lain. Sesudah kampung lain mendengarkan cerita ada Air panas pada tahun 1949 datanglah orang melayu sanggau yang bernama Nouman disitu berobati tujuh malam untuk mengobati penyakit kulit. Selain itu masyarakat juga percaya bahwa sumber air panas Ai Sipatn Lotup Peruntan tidak ada kepercayaan yang menggangu serta air tersebut memilki sejarah bahwa didaerah kawasan tersebut membuktikan ternyata airnya benr-benar panas dan mendidih.

\section{Pilihan kegiatan rekreasi}

Kawasan Sumber Air Panas Ai Sipatn Lotup Peruntan menurut beberapa responden menilai dikawasan objek dapat dijadikan kegiatan fotografi terutama didalam kawasan yang akan berfoto didekat Sumber Air Panas Ai Sipatn Lotup Peruntan. Selain itu juga dapat dilakukan kegiatan berkemah karena suasanannya nyaman dan sejuk.

\section{Kebersihan udara dan lokasi bersih tidak ada pengaruh}

Kawasan Sumber Air Panas Ai Sipatn Lotup Peruntan.berdasarkan analisis dari beberapa responden menilai dikawasan objek wisata bebas dari sampah dan coret-coret yang menggangu kebersihan udara dan pemandangan disekitar lokasi. Untuk menuju objek wisata dapat ditempuh menggunakan motor dan mobil, selain itu objek wisata sangat jauh dari pemukiman penduduk hingga bebas dari binatang yang mengganggu.

\section{Keamanan}

Berdasarkan analisis dari beberapa responden, kawasan Sumber Air Panas Ai Sipatn Lotup Peruntan bebas dari penebangan liar yang berada di sekitar kawasan, selain itu dikawasan tersebut tidak ada sama sekali pencurian karena lokasi yang bebas dari keramaian. Kawasan sumber air panas juga bebas sama sekali dari jalur berbahaya karena jalan yang dituju datar dan tidak ada munguk pada saat hujan pun tidak licin juga.

\section{Kenyamanan}

Berdasarkan analisis dari beberapa responden disekitar Sumber Air Panas Ai Sipatn Lotup Peruntan bahwa tempat objek wisata bebas dari bau-bau yang dapat mengganggu kenyamanan dalam kesantaian di objek wisata Sumber Air Panas Ai Sipatn Lotup Peruntan. Selain itu udara juga sangat sejuk karena vegetasi disekitar kawasan sumber air panas masih terjaga.

Pada penilaian objek daya tarik wisata Sumber Air Panas Ai Sipatn Lotup Peruntan pada unsur terlihat bahwa Keindahan Alam memiliki skor tertinggi yaitu 27,12 , jenis sumber daya alam yang menonjol memiliki nilai skor 23,63 dan Kepekaan sumber daya alam 22,12. Salah satu unsur yang menarik adalah keanekaragaman flora yaitu jenis anggrek yang tumbuh alami jenis anggrek antara lain. Jenis anggrek yang di temukan antara lain ada dua yaitu jenis Dendrobium compressum dan Lusia curtisii. 
Vol. 7 (1) : 372 - 378

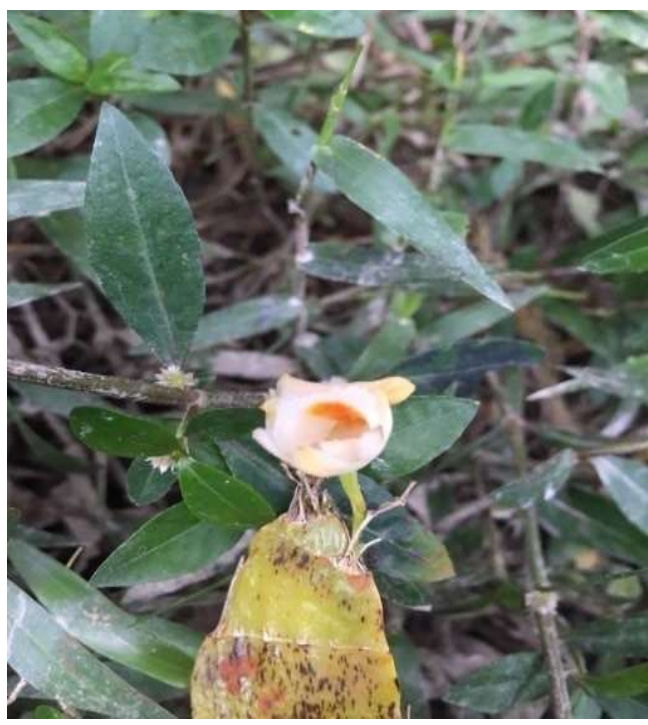

a

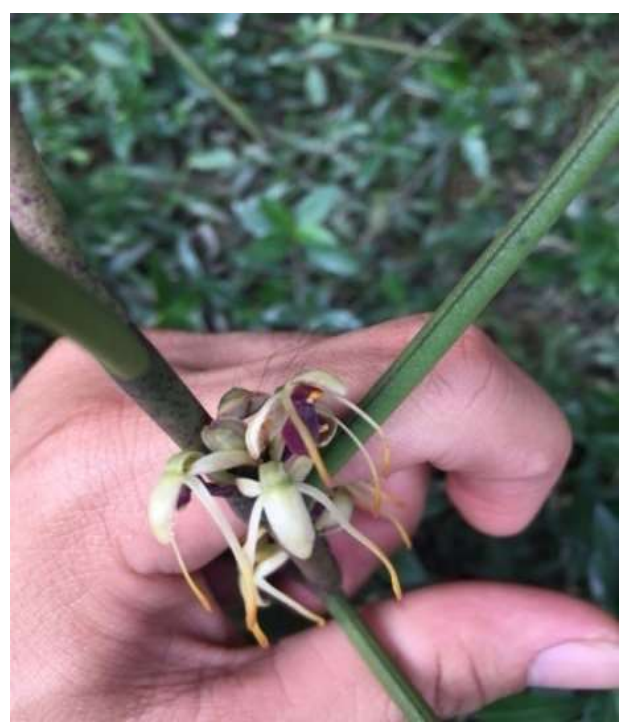

b

Gambar 1. Jenis anggrek yang ditemukan di Ai Sipatn Lotup Peruntan yaitu; a. Dendrobium compressum, b. Lusia curtisii

KESIMPULAN

Sumber air panas Ai Sipatn Lotup Peruntan memiliki potensi daya tarik dengan skor/nilai 943,98 atau berkategori sedang (B). dengan nilai tertinggi unsur Keindahan Alam 27,12 dan Jenis Sumber Daya Alam Yang Menonjol yaitu 23,63.

\section{DAFTAR PUSTAKA}

[PHKA] Perlindungan Hutan dan Konservasi Alam 2003. Pedoman Analisis Daerah Operasi Obyek dan Daya Tarik Wisata Alam (ADO-ODTWA). Direktorat
Jendral Perlindungan Hutan dan Konservasi Alam.Bogor.

Aryanto. 2003. Eviromental Marketing Pada Ekowisata Pesisir Menggerakkan Rakyat Daerah Otonom. Alfabeta. Jakarta.

Kodhyat, H. 1996. Sejarah Pariwisata dan Perkembangannya di Indonesia. PT. Gramedia Widiasarana Indonesia. Jakarta.

Musatafa H. 2000. Teknik Sampling. http: // home. unpar / hasan / Sampling.doc. [ diunduh 10 Juni 2014 ] 